\title{
Style investing
}

\section{Citation}

Barberis, Nicholas, and Andrei Shleifer. 2003. Style Investing. Journal of Financial Economics 68, no. 2: 161-199. doi:10.1016/s0304-405x(03)00064-3.

\section{Published Version}

doi:10.1016/S0304-405X(03)00064-3

\section{Permanent link}

http://nrs.harvard.edu/urn-3:HUL.InstRepos:30747193

\section{Terms of Use}

This article was downloaded from Harvard University's DASH repository, and is made available under the terms and conditions applicable to Other Posted Material, as set forth at http:// nrs.harvard.edu/urn-3:HUL.InstRepos:dash.current.terms-of-use\#LAA

\section{Share Your Story}

The Harvard community has made this article openly available.

Please share how this access benefits you. Submit a story.

Accessibility 

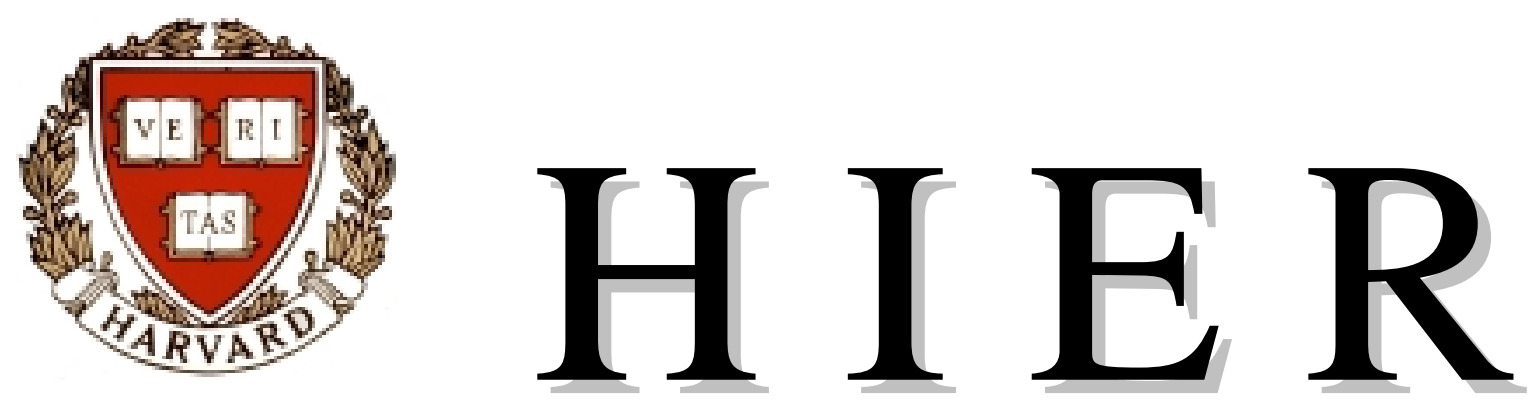

\title{
Harvard Institute of Economic Research
}

\author{
Discussion Paper Number 1908
}

\section{Style Investing}

\author{
By
}

Nicholas Barberis and Andrei Shleifer

December 2000

\section{Harvard University Cambridge, Massachusetts}

This paper can be downloaded without charge from the Social Science Research Network electronic library at: http://papers.ssrn.com/paper.taf?abstract_id=255557 


\title{
Style Investing
}

\author{
Nicholas Barberis and Andrei Shleifer \\ University of Chicago and Harvard University
}

\author{
This Draft: November 2000*
}

\begin{abstract}
We study asset prices in an economy where some investors classify risky assets into different styles and move funds back and forth between these styles depending on their relative performance. Our assumptions imply that news about one style can affect the prices of other apparently unrelated styles, that assets in the same style will comove too much while assets in different styles comove too little, and that high average returns on a style will be associated with common factors for reasons unrelated to risk. They also lead to a rich pattern of own- and cross- autocorrelations, sample premia that can be very different from true premia, and imply that style momentum strategies will be profitable. We use our model to shed light on many puzzling features of the data.
\end{abstract}

*We have benefited from discussions with John Campbell, Doug Diamond, Eugene Fama, Edward Glaeser, Sanford Grossman, Rafael La Porta, David Laibson, Sendhil Mullainathan, Geert Rouwenhorst, Lawrence Summers and Jeffrey Wurgler. 


\section{Style Investing}

We study asset prices in an economy where some investors classify risky assets into different styles and move funds back and forth between these styles depending on their relative performance. Our assumptions imply that news about one style can affect the prices of other apparently unrelated styles, that assets in the same style will comove too much while assets in different styles comove too little, and that high average returns on a style will be associated with common factors for reasons unrelated to risk. They also lead to a rich pattern of own- and crossautocorrelations, sample premia that can be very different from true premia, and imply that style momentum strategies will be profitable. We use our model to shed light on many puzzling features of the data. 


\section{Introduction}

One of the clearest elements of human thought is classification: the grouping of objects into categories. We group countries into democracies and dictatorships based on features of political systems within each group. We classify occupations as blue collar or white collar based on whether people work primarily with their hands or with their heads. We put foods into categories such as proteins and carbohydrates based on their nutritional characteristics. Such categorization simplifies our thinking, and enables us to process vast amounts of information reasonably efficiently. Mullainathan (2000) provides an innovative analysis of the implications of categorization for decision making.

Classification of large numbers of objects into categories is pervasive in financial markets. Investors classify assets as liquid securities such as stocks and bonds or illiquid ones, such as real estate and venture capital. They classify stocks as domestic or international, small or large, growth or value, "old economy" or "new economy", cyclical or non-cyclical. Such groups of securities are often called "asset classes" or "styles." Portfolio allocation based on selection among styles rather than among individual securities is known as "style investing."

When classifying securities into styles, investors group together assets that appear to be similar, in the sense that they are perceived to have a common characteristic. ${ }^{1}$ In some cases, the characteristic is an obvious one: the country in which the security is traded, the industry in which the firm operates, or a permanent legal characteristic. In other instances, a less obvious characteristic is used as the basis for a style, often because securities with that characteristic are found to have performed well historically. "Value investing" in equities emerged as a distinctive style over the last century following the work of Graham and Dodd (1934) on high dividend yield stocks, and the spectacular performance of some of the investors who followed their advice. Academic work documenting the superior performance of securities with a common characteristic can accelerate the formation of a style, as happened with the discovery of the "small firm" effect by Banz in the late 1970s. Over time, new styles appear and old styles die off. Railroad bonds were a very important asset class a century ago, forming the foundation of many institutional portfolios; they are no longer an identifiable asset class today (Swensen 2000).

Some of the characteristics used to define styles bear on fundamental values, and are thus of clear relevance to rational investors. For instance, U.S. government bonds are backed by the full faith and credit of the U.S. government, and hence as an asset class provide a good guarantee against financial trauma. Other styles are defined by characteristics of more dubious relevance to rational valuation. For example, it is not clear why stocks of companies with comparable market capitalizations should be grouped together in an asset

\footnotetext{
${ }^{1}$ See Rosch and Lloyd (1978) and Wilson and Keil (1999) for a discussion of the importance of similarity in the formation of categories.
} 
class defined by "size," since the firms these stocks are claims on have little in common fundamentally. Likewise, it is far from clear for what fundamental reason closed end funds, which might hold different securities trading in different countries, represent a meaningful asset class called "closed-end funds," but they do.

The importance of style investing has grown in recent years, as institutional investors, such as pension funds, foundations, and endowments, have come to dominate financial markets. The focus on styles is particularly attractive to institutional investors, because it enables them to organize and simplify their portfolio allocation decisions, as well as to measure and evaluate the performance of professional managers relative to standardized style benchmarks. From these agency perspectives, as well as from the viewpoint of diversification, style investing is preferred to the less disciplined and more qualitative approaches. Not surprisingly, the financial services industry has responded to this demand for "style investing." Most pension fund managers, as well as some mutual fund managers catering to the needs of individual investors, now identify themselves as following particular investment styles, such as growth, value, or technology. ${ }^{2}$ Indeed, recent authoritative guidebooks to institutional portfolio management are organized squarely around asset classes, and issue recommendations for prudent investment management in the form of portfolio allocation among styles (Bernstein 1995, Swensen 2000).

The growing importance of style investing points to the usefulness of assessing its effect on financial markets and security valuation. In this paper, we present a simple model that allows for such an assessment. The model combines style-based portfolio selection strategies of investors with a plausible mechanism for how these investors choose among styles. Specifically, we assume that many investors get into styles that have performed well in the past and out of styles that have performed badly, and that these fund flows affect prices. We use the model to shed light on a number of puzzling historical episodes in financial markets, to interpret a broad range of empirical findings already available in the literature and also to suggest some new empirical predictions.

Style investing has a number of implications for asset prices. Fundamentally unrelated securities will move together simply because they have been grouped into the same asset class: since style investors allocate funds at the level of a style, they generate coordinated demand shocks across all assets in the style, leading to comovement in prices even if there is none in fundamentals. This might explain why closed end mutual funds listed on the same exchange but holding completely different securities move together (Lee et al. 1991), or why identical securities listed on different exchanges move out of sync with each other (Froot and Dabora 1999). It might also explain why broad groups of securities categorized into the same style, such as small stocks or value stocks, comove more than can be explained by

\footnotetext{
${ }^{2}$ Goetzmann et. al. (2000) present data on mutual fund investors moving their funds among different styles.
} 
the comovement of their fundamentals (Fama and French 1995). Some of the most striking predictions of the theory emerge from the analysis of comovement.

Beyond that, our framework suggests that superior returns on a group of securities may lead to the formation of an asset class that includes these securities, and therefore cause them to move together in the future. There can thus be a positive association between superior returns and common movement in prices, which has nothing to do with risk. Even if this comovement is interpreted as a source of risk, it is a risk arising from resources moving in and out of styles, and is therefore investor-induced rather than fundamental risk (see De Long et. al. 1990b).

In our model, style investing generally produces life cycles of investment styles. The birth of a style is often triggered by good fundamental news about the securities in a style. The style then matures as its good performance recruits new funds, further raising the prices of securities belonging to the style. Finally, the style collapses, either because of arbitrage or because of bad fundamental news. Over time, the style may be reborn.

In many ways, this description of the life-cycle of investment styles is closely related to Kindleberger's (1978) view of bubbles, and leads to similar predictions. For example, returns on styles are positively autocorrelated at short horizons and mean revert in the long run. Individual securities also exhibit these properties, but in our model, this is simply a reflection of style level phenomena. Recent evidence that industry effects explain much of the momentum in individual stocks is consistent with this view (Moskowitz and Grinblatt 1999). Our model shows that fund flows between styles are one plausible source of such style-wide momentum effects.

Another important consequence of style investing is a negative externality among styles, which arises as fund recruitment by one style drives resources out of competing styles, and depresses prices of securities in them. This negative externality from successful styles explains some puzzling historical experiences, such as the poor performance of value stocks during 1998-1999 despite good earnings (Chan, Karceski, Lakonishok, 2001). One way to explain this episode is to point to the extraordinarily good performance of growth stocks during this period, and to recognize that this may have generated a substantial flow of resources out of value investing and into growth investing. More generally, this negative externality predicts insufficient comovement between securities belonging to different styles relative to the comovement of their fundamentals, as well as negative short run cross-autocorrelations between styles.

The effects that we study result from one of three factors: from investors' policy of allocating funds at the style level rather than at the individual asset level; from trend-chasing, where investors allocate more resources to styles with strong prior records; and finally, from the externality, whereby investors finance a shift into successful styles by withdrawing re- 
sources from poorly performing ones.

Of these three factors, only one, trend-chasing, has received much prior attention in the literature. De Long, Shleifer, Summers and Waldmann (1990a) consider a model with trend-chasing investors, but their focus is on how prices are affected when more sophisticated arbitrageurs are added into this mix. Hong and Stein (1999) analyze a model with "momentum traders," whose demand is based on past performance. They focus on time series autocorrelations in individual stock returns. None of these papers studies the effect of classifying assets into styles, nor of the externality between styles. In part this is because these issues arise in multi-asset economies, while earlier research has typically worked with only a single asset.

\section{$2 \quad$ A Model of Style Investing}

We consider a model with two kinds of investors, "switchers" and "fundamental traders." Switchers exhibit two features that are becoming increasingly important in financial markets. First, their demand for assets is expressed at the level of a style. We think of a style as a group of securities with a common characteristic. For example, large stocks are a style, as are value stocks, small stocks, or all stocks within a particular industry, country, or index.

The second feature of switchers is that the amount they allocate to a style depends on the style's past performance relative to other styles. Each period, switchers allocate more funds to styles with better than average performance and finance these additional investments by taking funds away from styles with below average performance.

To formalize these ideas, suppose that there are $2 n$ risky assets in fixed supply, and a riskfree asset, cash, in perfectly elastic supply and with zero net return. Suppose also that all risky assets belong to one of two styles: the first $n$ assets are in style $X$ and the remaining $n$ in style $Y$; it may help to think of these styles as "old economy stocks" and "new economy stocks", say.

Importantly, we assume that each security belongs to only one style. More generally, a given security may belong to multiple overlapping styles. A small bank stock with a low price earnings ratio may be part of a small stock style, a financial industry style, and a value style. A model capturing such overlaps can be constructed and would yield similar but less transparent predictions.

Following Hong and Stein (1999), we model risky asset $i$ as a claim to a single liquidating dividend $D_{i, T}$ to be paid at some later time $T$. The eventual dividend equals

$$
D_{i, T}=D_{i, 0}+\varepsilon_{i, 1}+\ldots+\varepsilon_{i, T}
$$


where $\varepsilon_{i, t}$ represents news about the final cashflow that is released at time $t$. We assume

$$
\varepsilon_{t}=\left(\varepsilon_{1, t}, \ldots, \varepsilon_{2 n, t}\right) \sim N\left(0, \Sigma_{D}\right) \text {, i.i.d over time. }
$$

The price of a share of risky asset $l$ at time $t$ is $P_{l, t}$ and the return on the asset between time $t-1$ and time $t$ is written ${ }^{3}$

$$
\Delta P_{l, t}=P_{l, t}-P_{l, t-1}
$$

As a measure of the value of style $X$ at time $t$, we use $P_{X, t}$, defined as the average price of a share across all assets in style $X$ :

$$
P_{X, t}=\frac{1}{n} \sum_{l \in X} P_{l, t}
$$

The return on style $X$ between time $t-1$ and time $t$ is

$$
\Delta P_{X, t}=P_{X, t}-P_{X, t-1}
$$

To capture the idea that switchers allocate funds at the level of a style, and do so using relative past performance, we write switcher demand for shares of an asset $i$ in style $X$ at time $t$ as

$$
N_{i, t}^{S}=\frac{1}{n}\left[A_{X}+\sum_{k=1}^{t-1} \theta^{k-1}\left(\frac{\Delta P_{X, t-k}-\Delta P_{Y, t-k}}{2}\right)\right],
$$

where $A_{X}$ and $\theta$ are constants, with $0<\theta<1$.

Symmetrically, switcher demand for shares of an asset $j$ in style $Y$ at time $t$ is

$$
N_{j, t}^{S}=\frac{1}{n}\left[A_{Y}+\sum_{k=1}^{t-1} \theta^{k-1} \frac{\left(\Delta P_{Y, t-k}-\Delta P_{X, t-k}\right)}{2}\right] .
$$

In words, when deciding on their time $t$ allocation, switchers compare style $X$ 's and style $Y$ 's return between time $t-2$ and time $t-1$, between time $t-3$ and time $t-2$, and so on, with the most recent past being given the most weight. They then move funds towards the style with the better prior record, buying an equal number of shares of each asset in that style, and reduce their holdings of the other style. The parameter $\theta$ determines how far back switchers look when comparing the past performance of styles, and hence indirectly, the persistence of their flows. $A_{X}$ can be thought of as switchers' long run target demand for style $X$, from which they deviate based on the relative performance of styles. The fact

\footnotetext{
${ }^{3}$ For simplicity, we abuse terminology slightly and refer to the asset's change in price as its return.
} 
that the demand for all assets within a style is the same underscores the fact that switchers allocate funds at the style level and do not distinguish among assets within the same style. ${ }^{4}$

The relative performance feature in (5) and (6) can be motivated in a number of different ways. In this paper, we think of it as arising from two underlying factors: first, adaptive expectations, whereby investors base their forecasts of future style returns in part on past returns; and second, a reluctance on the part of investors to let their overall allocation to equities drift too far from a preset target level. More broadly, this second condition means that investors are more willing to move between different equity styles than they are to change their overall allocation to stocks. This is indeed true of institutional investors, who try to maintain their allocations to the broadest asset classes close to predetermined targets. ${ }^{5}$ To some extent, it may also describe the behavior of individual investors: people sometimes decide to keep the fraction of their wealth devoted to equities constant over time, even though they move this money among different investment styles.

In the Appendix, we show more formally that adaptive expectations combined with a constraint on overall equity holdings lead to a relative performance feature like that in (5) and (6). The intuition is straightforward. Holding everything else constant, an increase in $\Delta P_{X, t-1}$, style $X$ 's most recent past return, leads switchers to forecast higher returns on style $X$ in the future, and hence to increase their demand for style $X$ at time $t$. However, since they want to keep their overall allocation to equities unchanged, they have to sell shares of style $Y$ in order to finance their additional investment in $X$. Therefore, $\Delta P_{X, t-1}$ has an equal and opposite effect on $N_{i, t}^{S}$ in (5) and $N_{j, t}^{S}$ in (6), making demand a function of relative past performance.

Adaptive expectations are just one way of motivating the trend-chasing that switchers engage in. Portfolio insurance strategies generate similar investment patterns. As important, an institutional investor, such as the sponsor of a defined benefit plan, may hire money managers with strong prior records and fire those with poor performance simply because such strategies are easier to justify ex-post to those monitoring their actions. Such agency considerations therefore lead to trend-chasing too.

In general, investors have more than two styles to choose from. One possible extension of (5) to the case of $M>2$ styles is to write switcher demand for a risky asset $i$ in style $m$ as

$$
N_{i, t}^{S}=\frac{1}{n}\left[A_{m}+\sum_{k=1}^{t-1} \theta^{k-1}\left(\Delta P_{X_{m}, t-k}-\frac{1}{M} \sum_{l=1}^{M} \Delta P_{X_{l}, t-k}\right)\right],
$$

\footnotetext{
${ }^{4}$ The strategies in (5) and (6) are not self-financing. Rather, we assume that at the start of each period, switchers are endowed with sufficient resources to fund their strategies. This allows us to abstract from issues which are not our main focus here - the long run survival of switchers, for example - and to concentrate on understanding the behavior of prices when switchers do play a role in setting them.

${ }^{5}$ See Swensen (2000) for more discussion of institutional investor behavior.
} 
where $\Delta P_{X_{l}, t-k}$ is the return on style $l$, so that the allocation to an asset in style $m$ depends on how that style does relative to the average performance of all styles.

Even when there are many styles, the two style formulation in (5) may still be relevant. Styles often come in natural pairs: stocks with a high value of some characteristic constitute one style, and stocks with a low value of the same characteristic, the other. In these pair situations, by far the most important competitor for one style is its twin, making the pairwise comparison in (5) more relevant. Put differently, if investors tilt towards a growth style, it seems more likely that they will finance this by withdrawing funds from its natural competitor, value, than by withdrawing a smaller amount from all other styles, as (7) implies. The formulation in (7) is more relevant for industry styles, when any one industry has many natural competing styles.

The second type of investor in our model is a fundamental trader. They act as arbitrageurs, and try to prevent the price of an asset from deviating too far from its expected final dividend. To formalize this, suppose that at the start of each period, fundamental traders are given an amount $W^{F}$ to allocate. We suppose that they have CARA preferences defined over the value of their invested funds one period later, and take price changes to be normally distributed. Since they have no constraints on their allocations, they solve

$$
\max _{N_{t}} E_{t}^{F}\left(-\exp \left[-\gamma\left(W^{F}+N_{t}^{\prime}\left(P_{t+1}-P_{t}\right)\right)\right]\right)
$$

where

$$
N_{t}=\left(N_{1, t}, \ldots, N_{2 n, t}\right)^{\prime}
$$

is a vector of the number of shares allocated to each risky asset, $\gamma$ governs the degree of risk aversion, $E_{t}^{F}$ denotes fundamental trader expectations at time $t$, and

$$
P_{t}=\left(P_{1, t}, \ldots, P_{2 n, t}\right)^{\prime}
$$

Optimal holdings $N_{t}^{F}$ are given by

$$
N_{t}^{F}=\frac{\left(V_{t}^{F}\right)^{-1}}{\gamma}\left(E_{t}^{F}\left(P_{t+1}\right)-P_{t}\right)
$$

where

$$
V_{t}^{F}=\operatorname{var}_{t}^{F}\left(P_{t+1}-P_{t}\right),
$$

with the $F$ superscript again denoting a forecast made by fundamental traders.

We summarize switcher demand for the $2 n$ assets by $N_{t}^{S}$, a $2 n \times 1$ vector,

$$
N_{t}^{S}=\left(\frac{N_{X, t}^{S}}{n}, \ldots, \frac{N_{X, t}^{S}}{n}, \frac{N_{Y, t}^{S}}{n}, \ldots, \frac{N_{Y, t}^{S}}{n}\right)^{\prime},
$$


with

$$
N_{X, t}^{S}=A_{X}+\sum_{k=1}^{t-1} \theta^{k-1}\left(\frac{\Delta P_{X, t-k}-\Delta P_{Y, t-k}}{2}\right),
$$

and

$$
N_{Y, t}^{S}=A_{Y}+\sum_{k=1}^{t-1} \theta^{k-1}\left(\frac{\Delta P_{Y, t-k}-\Delta P_{X, t-k}}{2}\right),
$$

in line with (5) and (6).

Given fundamental trader expectations about future prices, which we discuss shortly, prices are set as follows. The fundamental traders double up as market makers and treat the demand from switchers as a supply shock. If total supply of the $2 n$ assets is given by the vector $Q$, equations (9) and (10) imply

$$
P_{t}=E_{t}^{F}\left(P_{t+1}\right)-\gamma V_{t}^{F}\left(Q-N_{t}^{S}\right) \text {. }
$$

In contrast to switchers, who form expectations of future prices based on past prices, fundamental traders are forward looking and base price forecasts on expectations about the final dividend. One way they may do this is to roll equation (13) forward iteratively, setting

$$
E_{T-1}^{F}\left(P_{T}\right)=E_{T-1}^{F}\left(D_{T}\right)=D_{T-1}
$$

where

$$
D_{t}=\left(D_{1, t}, \ldots, D_{2 n, t}\right)^{\prime}
$$

This leads to

$$
P_{t}=D_{t}-\gamma V_{t}^{F}\left(Q-N_{t}^{S}\right)-E_{t}^{F} \sum_{j=1}^{T-t-1} \gamma V_{t+j}^{F}\left(Q-N_{t+j}^{S}\right)
$$

We now suppose that fundamental traders conjecture that the equilibrium unconditional covariance matrix of returns is $V$, and that switcher demand $N_{t}^{S}$ has a finite long run mean $\bar{N}^{S}$. They then set

$$
V_{t}^{F}=V, \forall t
$$

and

$$
E_{t}^{F}\left(N_{t+j}^{S}\right)=\bar{N}^{S}
$$

The first assumption in (15) is innocuous, while (16) has economic importance: it says that while fundamental traders recognize the existence of a supply shock due to switchers, they are not sophisticated enough to figure out its time series properties. Our assumptions imply

$$
P_{t}=D_{t}-\gamma V\left(Q-N_{t}^{S}\right)-(T-t-1) \gamma V\left(Q-\bar{N}^{S}\right)
$$

Dropping the non-stochastic terms, we obtain

$$
P_{t}=D_{t}+\gamma V N_{t}^{S}
$$


The exogeneous parameters in our model are the cashflow covariance matrix $\Sigma_{D}$, switchers' demand parameters $A_{X}, A_{Y}$, and $\theta$, and fundamental traders' risk aversion $\gamma$. We study equilibria in which these exogeneous parameters, combined with fundamental traders' conjecture about the covariance matrix of returns and about switchers' mean demand lead, through (18), to prices which confirm fundamental traders' original conjecture.

Note that in a world with only fundamental traders,

$$
P_{t}=D_{t}
$$

We refer to this as the fundamental value of the assets and denote it $P_{t}^{*}$.

Equation (18) shows that fundamental traders are not able to push prices back to fundamental value. This is consistent with earlier research by De Long et. al. (1990b) and Shleifer and Vishny (1997) who show that fundamental risk and noise trader risk - the risk that a mispricing will worsen before it corrects - limit the size of arbitrageur positions and allow noise traders to affect prices. It is also consistent with the substantial body of empirical evidence indicating that uninformed demand shocks influence security prices (Harris and Gurel 1986, Shleifer 1986, Froot and Dabora 1999, Kaul, Mehrotra, and Morck 2000, and Lamont and Thaler 2000).

Even if we were to include more sophisticated arbitrageurs in our model - in particular, arbitrageurs who understand the form of the demand function (5) - it is not clear that they would counteract the mispricing to any greater degree; on the contrary, they might exacerbate it. This is the finding of De Long et. al. (1990a), who consider an economy with positive feedback traders - similar in some ways to our switchers - as well as arbitrageurs. When an asset's price rises above fundamental value, the arbitrageurs do not sell or short the asset. Rather, they buy it, knowing that the extra upward jolt to the price that this causes will attract more feedback traders, leading to still higher prices, at which point the arbitrageurs can exit at a profit. This suggests that sophisticated arbitrageurs may amplify, rather than counteract the effect of switchers, and so for simplicity, we exclude them from our model.

With additional assumptions, (18) can be simplified further. In this paper, we restrict attention to simple cashflow covariance structures where all assets have a cashflow news variance of one, where the pairwise cashflow correlation between any two assets in the same style is the same, and where the pairwise cashflow correlation between any two assets in different styles is the same:

$$
\begin{aligned}
& \operatorname{cov}\left(\varepsilon_{i, t+1}, \varepsilon_{j, t+1}\right)=1, i=j \\
& \operatorname{cov}\left(\varepsilon_{i, t+1}, \varepsilon_{j, t+1}\right)=r_{1}, i \neq j, i, j \text { in the same style, } \\
& \operatorname{cov}\left(\varepsilon_{i, t+1}, \varepsilon_{j, t+1}\right)=r_{2}, i \neq j, i, j \text { in different styles. }
\end{aligned}
$$


We find that in this case, there is an equilibrium in which the covariance matrix of returns has a similar form,

$$
\begin{aligned}
& \operatorname{cov}\left(\Delta P_{i, t+1}, \Delta P_{j, t+1}\right)=\sigma^{2}, i=j \\
& \operatorname{cov}\left(\Delta P_{i, t+1}, \Delta P_{j, t+1}\right)=\sigma^{2} \rho_{1}, i \neq j, i, j \text { in the same style, } \\
& \operatorname{cov}\left(\Delta P_{i, t+1}, \Delta P_{j, t+1}\right)=\sigma^{2} \rho_{2}, i \neq j, i, j \text { in different styles. }
\end{aligned}
$$

In other words, all assets have the same return variance, the pairwise return correlation between any two assets in the same style is the same, and the pairwise return correlation between any two assets in different styles is the same.

Substituting this covariance structure into (18), we find that up to a constant, the price of an asset $i$ in style $X$ is

$$
\begin{aligned}
P_{i, t} & =D_{i, t}+\gamma \sigma^{2}\left(1-\rho_{1}+n\left(\rho_{1}-\rho_{2}\right)\right) \frac{N_{X, t}^{S}}{n} \\
& =D_{i, t}+\frac{1}{\phi} \sum_{k=1}^{t-1} \theta^{k-1}\left(\frac{\Delta P_{X, t-k}-\Delta P_{Y, t-k}}{2}\right),
\end{aligned}
$$

where

$$
\phi=\frac{n}{\gamma \sigma^{2}\left(1-\rho_{1}+n\left(\rho_{1}-\rho_{2}\right)\right)} .
$$

\subsection{Parameter Values}

The results in the remainder of the paper are based on a numerical implementation of (22) in which the exogeneous parameters $\Sigma_{D}, A_{X}, A_{Y}$, and $\theta$ are assigned specific values. To construct $\Sigma_{D}$, we suppose that the cashflow shock to an asset has three components: a marketwide cashflow factor which affects assets in both styles, a style-specific cashflow factor which affects assets in one style but not the other, and a completely idiosyncratic cashflow shock specific to a single asset. Formally, for $i \epsilon X$,

$$
\varepsilon_{i, t+1}=\psi_{M} f_{M, t+1}+\psi_{S} f_{X, t+1}+\sqrt{\left(1-\psi_{M}^{2}-\psi_{S}^{2}\right)} f_{i, t+1},
$$

and for $j \epsilon Y$,

$$
\varepsilon_{j, t+1}=\psi_{M} f_{M, t+1}+\psi_{S} f_{Y, t+1}+\sqrt{\left(1-\psi_{M}^{2}-\psi_{S}^{2}\right)} f_{j, t+1},
$$

where $f_{M, t+1}$ is the market-wide factor, $f_{X, t+1}$ and $f_{Y, t+1}$ are the style-specific factors, and $f_{i, t+1}$ and $f_{j, t+1}$ are the idiosyncratic factors; $\psi_{M}$ and $\psi_{S}$ are constants which control the relative importance of the three components. We suppose that each factor has the same unit variance and is orthogonal to the other factors. This implies the following cashflow covariance structure:

$$
\begin{aligned}
& \operatorname{corr}\left(\varepsilon_{i, t+1}, \varepsilon_{j, t+1}\right)=1, i=j \\
& \operatorname{corr}\left(\varepsilon_{i, t+1}, \varepsilon_{j, t+1}\right)=\psi_{M}^{2}+\psi_{S}^{2}, i \neq j, i, j \text { in the same style, } \\
& \operatorname{corr}\left(\varepsilon_{i, t+1}, \varepsilon_{j, t+1}\right)=\psi_{M}^{2}, i \neq j, i, j \text { in different styles. }
\end{aligned}
$$


The numerical example that we use for our analysis sets $\psi_{M}=0.25$, and $\psi_{S}=0.5$. In this case, the cashflow covariance matrix is given by

$$
\Sigma_{D}=\left(\begin{array}{cc}
A & B \\
B & A
\end{array}\right)
$$

with

$$
A=\left(\begin{array}{llll}
1 & 0.31 & \cdots & 0.31 \\
0.31 & \ddots & \ddots & \vdots \\
\vdots & \ddots & \ddots & 0.31 \\
0.31 & \cdots & 0.31 & 1
\end{array}\right), B=\left(\begin{array}{llll}
0.06 & \cdots & \cdots & 0.06 \\
\vdots & \ddots & & \vdots \\
\vdots & & \ddots & \vdots \\
0.06 & \cdots & \cdots & 0.06
\end{array}\right)
$$

The remaining parameters are set equal to

$$
\begin{aligned}
A_{X} & =A_{Y}=0 \\
\theta & =0.95 \\
\gamma & =1.1
\end{aligned}
$$

Equation (5) shows that $\theta$ controls the persistence of switcher flows; we choose $\theta$ close to 1 so as to capture the kind of persistence in fund flows we think is important in financial markets. Fundamental trader risk aversion $\gamma$ is set so that in equilibrium, returns exhibit a level of excess volatility similar to what has been observed in historical U.S. data. In particular, for these parameter values, there is an equilibrium in which style returns have a standard deviation 1.3 times the standard deviation of cashflow shocks, a level of excess volatility that is reasonable given historical data. ${ }^{6}$ In this equilibrium, the value of $\phi$ in (23) is $1.25 .^{7}$

\section{Competition Among Styles}

As a first step to understanding the effect of switchers on asset prices, we use the price function in (22) to generate some impulse response functions. We take $n=50$, so that there are 100 stocks, the first 50 of which are in style $X$ and the last 50 in style $Y$. The parameters are set equal to the values in (24) and (25). Figure 1 shows how the prices $P_{X, t}$ and $P_{Y, t}$ of styles $X$ and $Y$, defined in (3), evolve after a one time cashflow shock to style $X$ when

\footnotetext{
${ }^{6}$ For example, the standard deviation of aggregate dividend growth over 1926-1995 is around 12\% while the standard deviation of aggregate stock returns over the same period is around $20 \%$.

${ }^{7}$ The parameter values in (24) and (25) also support other equilibria, including one where returns are only slightly more volatile than cashflows. The intuition is that if fundamental traders think that returns are not very volatile, they will trade against switchers more aggressively, with the result that equilibrium returns will indeed have low volatility. To support the equilibrium described in the main text, we need fundamental traders to expect returns to be substantially more volatile than cashflows. Reassuringly, all the results in this paper remain qualitatively valid across multiple equilibria.
} 
$t=1$. In other words, for $i \epsilon X, \varepsilon_{i, 1}=1, \varepsilon_{i, t}=0, t>1$, and for $j \epsilon Y, \varepsilon_{j, t}=0, \forall t$. The initial expected cashflow is $D_{i, 0}=50, \forall i$.

The solid line in the top half of the graph tracks $P_{X, t}$, the value of style $X$ in the presence of switchers. The dashed line in the top half is the fundamental value of style $X$, $P_{X, t}^{*}$, defined through equations (19) and (3) as the value of style $X$ when there are only fundamental traders in the economy and no switchers.

The figure shows that in the presence of switchers, a cashflow shock to style $X$ leads to a substantial and long-lived deviation of $X$ 's price from its fundamental value. Intuitively, the good cashflow news about $X$ pushes up its price; this outperformance catches the attention of switchers, who increase their demand for $X$ in the following period, pushing $X$ 's price still higher, drawing in more switchers, and so on. $X$ may continue to have good returns for some time even if there is bad news about its fundamentals: while fundamental traders reduce their demand for $X$ after hearing the bad news, this may be more than compensated for by the persistent inflows from switchers.

The fact that investment decisions are based on relative rather than absolute past performance leads to a novel prediction which we refer to as an externality. Figure 1 shows that the cashflow shock to $X$ affects not only $X$ 's price, but also $Y$ 's, even though there has been no news about $Y$. The good news about $X$ draws funds into that style; however, since switchers want to maintain a constant overall allocation to equities, they finance the extra investment in $X$ by taking money out of $Y$. This pushes $Y$ 's price down, making it look even worse relative to $X$, leading to more redemptions by switchers, and so on. During this period, persistent outflows can make $Y$ will do badly even if it receives good news about its fundamentals.

In summary, Figure 1 shows that in our model, styles follow a specific life-cycle. A style $X$ is set in motion by good fundamental news about itself or alternatively by bad news about another style $Y$, which affects it through the externality. The style then swings away from fundamental value for a prolonged period, powered by fund flows attracted by its superior past performance. Finally, the style returns to fundamental value because of selling by fundamental traders, because of bad news about its own fundamentals, or most interestingly, because of good news in a competing style $Y$, which draws attention and investment dollars away from $X$.

Figure 2 illustrates these points in other way by showing how the prices of $X$ and $Y$ evolve over a 100 period segment of the simulated data. With switchers, the styles experience prolonged departures from fundamental values that are only gradually reversed.

In some cases, the cycles we describe may be reinforced by academic work analyzing the historical performance of a style. It is noteworthy that Banz' (1979) study on the 
outperformance of small cap stocks was followed by several years of strikingly good returns on that style. Our model would explain this by saying that Banz' study attracted the attention of switchers, who diverted funds to small stocks, pushing them higher, thus drawing in yet more switchers and leading to a long period of superior performance.

More radically, cycles may be set in motion as a result of data snooping, as analysts looking through historical data identify abnormal returns. When such analysts succeed in convincing investors that they have found strategies earning true superior returns, they will recruit new resources to the strategies, thereby confirming the anomaly, at least over a period of time. Perhaps the discovery of the size effect in the 1970's is an example of such creation of a style out of what might have been a fluke in the data.

The externality from style switching may be helpful in interpreting other recent evidence. During 1998 and 1999, value stocks performed extremely poorly by historical standards, lagging both growth stocks and the broad index by a significant margin. As Chan, Karceski, and Lakonishok (2001) show, this poor performance occurred despite the fact that the earnings growth of value stocks over this period was as high as that of growth stocks, and if anything unusually good by historical standards. In other words, the poor performance of value portfolios cannot be easily linked to their fundamentals. A more natural explanation comes from our theory: the poor performance of value stocks in 1998-1999 might have been due to the spectacular performance of large growth stocks which generated large flows of funds unrelated to fundamentals - into these stocks and out of value, the obvious competing style.

Another example comes, once again, from the historical performance of small stocks. Siegel (1999) argues that one reason for the vastly superior performance of small stocks relative to large stocks during 1975-1983 was the dismal performance of the seemingly invincible "Nifty Fifty" large cap stocks in 1973-74. The demise of these high profile large stocks left investors disenchanted with the large stock style and generated a flow of funds towards the competing style, small stocks, triggering a small stock cycle. A competing increase in the relative demand for large stocks, prompted by the rise of indexation and institutional investing more generally, may have arrested this wave of high small stock returns. According to Gompers and Metrick (2001), institutional investors prefer large stocks and their ownership of these stocks has increased rapidly in the last 20 years. This increase in demand for the competing style may be one reason for the poor relative performance of small stocks after 1983.

\section{The Behavior of Asset Prices}

We now present a systematic analysis of the effect of switcher flows on asset prices. As in Section 3 , we take $n=50$, so that there are 100 stocks, the first 50 of which are in style 
$X$ and the last 50 in style $Y$. For the parameter values in (24) and (25), we use the price formula (22) to simulate long time series of prices for the 100 assets, and then discuss the properties of individual asset returns $\Delta P_{l, t}$ and of style level returns $\Delta P_{X, t}$, defined in (2) and (4) respectively.

\subsection{Comovement within Styles}

Since switcher demand for securities is expressed at the level of a style, assets within a style comove more than their fundamentals do. If style $X$ has had superior past performance, switchers invest more in all securities in style $X$, pushing their prices up together. This coordinated demand generates comovement over and above that induced by cashflow news.

In our simulated data, the correlation matrix of returns is

$$
\operatorname{corr}\left(\Delta P_{1, t}, \ldots, \Delta P_{2 n, t}\right)=\left(\begin{array}{cc}
\widehat{A} & \widehat{B} \\
\widehat{B} & \widehat{A}
\end{array}\right),
$$

with

$$
\widehat{A}=\left(\begin{array}{llll}
1 & 0.46 & \cdots & 0.46 \\
0.46 & \ddots & \ddots & \vdots \\
\vdots & \ddots & \ddots & 0.46 \\
0.46 & \cdots & 0.46 & 1
\end{array}\right), \widehat{B}=\left(\begin{array}{llll}
-0.16 & \cdots & \cdots & -0.16 \\
\vdots & \ddots & & \vdots \\
\vdots & & \ddots & \vdots \\
-0.16 & \cdots & \cdots & -0.16
\end{array}\right)
$$

The average correlation between a pair of assets $i$ and $j$ which are in the same style is 0.46 in the presence of switchers; this is indeed higher than the cashflow correlation of 0.31 , reported in (24). When there are no switchers, return correlation is the same as cashflow correlation.

Our model suggests that fundamentally unrelated securities move together simply because they belong to the same style. There is a common factor in returns to such securities even if there is no common factor in their fundamentals. More generally, even if the fundamentals of the securities in the same style are correlated - as in our numerical example - the common factor in their returns is generally stronger than the common factor in their fundamentals.

This simple implication of style investing has significant consequences for our interpretation of security returns. Fama and French (1995) show that there is a striking common factor in the returns on value stocks as well as a clear common component in small stock returns. The rational pricing view of this comovement holds that it must be due to common factors in the underlying earnings of small stocks and value stocks. The difficulty with this explanation is that it is not clear why firms of similar market capitalization should for that very reason be fundamentally related, and hence why there should be a common component 
to their earnings. ${ }^{8}$ It is more plausible to argue that, to the extent that small firms belong to a style - either because size is a characteristic defining a style or because size is a characteristic defining exclusion from a competing style such as indexation - they will move together by virtue of fund flows in and out of that style. Even if there is a common component in the earnings of small firms for some reason, the common component in their returns should be much more pronounced. A similar prediction can be made for value stocks: there should be a style-induced common factor in returns that is clearer than the common factor in earnings.

The evidence of Fama and French (1995) is consistent with our analysis. Although they do find some evidence of a common factor in the fundamentals of small stocks, as well as in value stock fundamentals, these fundamental factors are weaker than the factors in returns. More importantly, there is little evidence that the return factors are driven by the fundamental factors.

In fact, it is possible to replicate Fama and French's results very closely using the simulated data from our model. Suppose that $X$ represents value stocks and $Y$, growth stocks. The regression Fama and French run to illustrate comovement in returns is

$$
R_{X, t}=\alpha+\beta_{1} R_{M, t}+\beta_{2} R_{S, t}+u_{X, t},
$$

where $^{9}$

$$
\begin{aligned}
R_{X, t} & =\frac{1}{n / 2} \sum_{l=n / 2+1}^{n} \Delta P_{l, t}, \\
R_{M, t} & =\frac{1}{2 n} \sum_{l=1}^{2 n} \Delta P_{l, t} \\
R_{S, t} & =\frac{1}{n / 2} \sum_{l=1}^{n / 2} \Delta P_{l, t}-\frac{1}{n / 2} \sum_{l=n+1}^{3 n / 2} \Delta P_{l, t} .
\end{aligned}
$$

Here, $R_{X, t}$ is the return on a portfolio consisting of half the available universe of $n$ value stocks; $R_{M, t}$ is the market factor, the average return of all $2 n$ stocks; and $R_{S, t}$ is a style factor, sometimes known as the HML factor, constructed as the return on a portfolio of the remaining value stocks minus the return on half the available growth stocks. The reason we sometimes use only half the stocks in a style is to ensure that $R_{X, t}$ and $R_{S, t}$ are constructed using different stocks and hence that spurious correlation is avoided.

When they run the above regression, Fama and French find that there is a market factor and a style factor in the returns of the value stock portfolio; put differently, they find that

\footnotetext{
${ }^{8}$ In principle, changes in discount rates can also generate comovement. However, changes in interest rates or risk aversion induce a common factor in the returns of all stocks, and do not explain why a particular group of stocks comoves. A common factor in news about the risk of the assets in a style may be a source of comovement, but there is no direct evidence to support this in the case of small and value stocks.

${ }^{9}$ In reading these equations, it may be helpful to recall that stocks numbered 1 through $n$ are in style $X$, while stocks $n+1$ through $2 n$ are in style $Y$.
} 
the return on the value stock portfolio loads positively on the market and style factors. The $R^{2}$ they obtain is over $90 \%$. In our simulated data, we find

$$
R_{X, t}=-0.005+1.00 R_{M, t}+0.48 R_{S, t}+u_{X, t}, R^{2}=92 \%
$$

a similar outcome.

Fama and French then examine whether the common factors in value stock returns are due to common factors in underlying fundamentals. Specifically, they construct a market fundamental factor $D_{M, t}$ and a style fundamental factor $D_{S, t}$ to mimic the return factors:

$$
\begin{aligned}
D_{M, t} & =\frac{1}{2 n} \sum_{l=1}^{2 n} \varepsilon_{l, t}, \\
D_{S, t} & =\frac{1}{n / 2} \sum_{l=1}^{n / 2} \varepsilon_{l, t}-\frac{1}{n / 2} \sum_{l=n+1}^{3 n / 2} \varepsilon_{l, t},
\end{aligned}
$$

and run a regression of $R_{X, t}$ on $D_{M, t}$ and $D_{S, t}$. Disappointingly, the $R^{2}$ falls to around 20\%: little of the comovement in returns appears to be due to comovement in fundamentals. Fama and French ascribe their results to mismeasurement of the fundamental factors. Undoubtedly, this is part of the problem, but style investing also provides a simple explanation. When we run this second regression in our simulated data, we obtain

$$
R_{X, t}=-0.005+1.00 D_{M, t}+0.48 D_{S, t}+u_{X, t}, R^{2}=50 \%,
$$

to some extent replicating the large drop in $R^{2}$ found by Fama and French. In other words, the style level factor $R_{S, t}$ may be largely due to style level flows of funds between $X$ and $Y$, and not to cashflow comovement.

Other evidence is also consistent with this analysis. Pindyck and Rotemberg (1990) show that there is comovement in prices of different commodities over and above what can be explained by economic fundamentals. Lee, Shleifer and Thaler (1991) find that the prices of closed end mutual funds move together even when their fundamentals are unrelated. They interpret this evidence as suggesting that closed end funds are generally traded by individual investors, and hence that their prices reflect the sentiment of such investors. In the language of the present model, if enough individual investors have trading styles that lead to the flow of funds in and out of closed end mutual funds, then the changes in the prices of these funds will reflect the common component of these investors' styles even when the fundamentals of the different funds have nothing in common.

Also relevant are the findings of Froot and Dabora (1999), who study "Siamese twin" stocks such as Royal Dutch and Shell. These stocks are claims to the same cashflow stream, but are traded in different locations: Royal Dutch in the U.S. and Shell in the U.K. In a frictionless market, these stocks should move together. Froot and Dabora show, however, 
that Royal Dutch is more sensitive to movements in the U.S. market while Shell comoves more with the U.K. market. A style based perspective provides a natural explanation: Royal Dutch, a member of the S\&P 500, is buffeted by the flows of investors for whom the S\&P 500 is a style and therefore comoves more with this index. For the same reason, Shell, a member of the FTSE index, comoves more with that index.

Our view of comovement has a number of other predictions and implications for the interpretation of empirical facts. Not only should stocks within a style comove more than their fundamentals do, but stocks that enter a style should comove more with the style after they are added to it than before. For example, a stock that is added to an index such as the S\&P 500 should comove more with the index after it is added than before. Changes in the pattern of comovement after a security is added to a style provide some of the clearest empirical predictions of the theory.

Interesting evidence about stocks entering new styles comes from European equity markets. Rouwenhorst (1999) notes that while money managers have traditionally allocated funds to European stocks at the country level, a growing number of them have started allocating funds by industry instead. Our model predicts that such a shift would make industry factors in returns relatively stronger and country factors relatively weaker. This is exactly the finding of Baca et. al. (2000) and Cavaglia et. al. (2000), who examine the importance of industry and country factors in European stock returns over time. Moreover, Rouwenhorst (1999) notes that when the shift to industry-level allocation began, country factors were still more important that industry factors. This suggests that the shift in allocation strategy generated the change in the structure of returns, rather than the other way around.

In the data, portfolio premia are often associated with comovement: small stocks and value stocks have each had high average returns and they both exhibit comovement. A frequent interpretation is that the comovement represents some kind of systematic risk which is then compensated by the observed premium. Our analysis suggests a different view. If an investment strategy is found to earn a premium, it may become labelled a "style", and mutual fund managers and institutional money managers will create products to facilitate investing in that style. The resulting flows of funds into the style will generate comovement. In other words the premia may lead to comovement, rather than the comovement leading to premia.

Even if the comovement in small stocks and value stocks does represent a form of systematic risk which ultimately generates a premium, our analysis suggests that at least part of this risk is induced by investors themselves through their style-based strategies, rather than being created by comovement in firm fundamentals. The risk is systematic even if it is not fundamental (De Long et. al 1990b).

The risk induced by style-based trading can have broader relevance in financial markets. 
For example, several writers have observed that emerging financial markets often move in tandem. This correlation rose during the financial crisis of 1998, when stock prices in nearly all emerging markets suffered substantial declines, even in countries fundamentally unaffected by the crisis. Such contagion may have been caused by across the board liquidation of emerging market portfolios by investors switching out of the emerging market style. Kaminsky et. al. (2000) find evidence of precisely such liquidations by mutual fund investors. The emerging markets crisis vividly illustrates how style investing can become a source of systematic risk, for both adherents to a style and for arbitrageurs. Precisely because all investors trading the affected securities are subject to this risk, price movements resulting in demand shifts from style investors can be a constant feature of financial markets, undeterred by arbitrage.

\subsection{Comovement Across Styles}

Two assets in the same style, then, will be more correlated than their underlying fundamentals. Interestingly, the opposite is true of two assets in different styles, asset $i$ in style $X$, say, and asset $j$ in style $Y$. Such assets will be less correlated than their underlying fundamentals. Comparing the correlation matrices in (24) and (26), we see that the average correlation between two assets in different styles is -0.16 in the presence of switchers, lower than the 0.06 cashflow correlation. The reason for this is the externality generated by switchers: a good return for style $X$ leads to a flow out of $Y$ and into $X$, driving the styles in opposite directions, and lowering the correlation between them. Figure 2 provides another view of the same phenomenon: the price paths of styles $X$ and $Y$ tend to move in opposite directions.

This result implies, for example, that the returns on small stocks and large stocks and the returns on value stocks and growth stocks should be pairwise less correlated than their fundamentals. Reality may be more complicated than this because there is overlap between styles. Competition between value and growth would suggest that their returns are less correlated than their fundamentals, but both value stocks and growth stocks are part of the overall U.S. stock market, itself a style. By the first result of this section, this would tend to make value and growth stocks more correlated than their cashflows.

In view of this complication, it is better to make our prediction in terms of market adjusted returns, or returns net of market returns. In other words, we predict that the market adjusted returns on value and growth stocks are less correlated than the fundamentals of value and growth stocks, in turn adjusted for market fundamentals.

One potential application of our result that different styles exhibit insufficient comovement is to stocks and bonds themselves. A number of authors (Barsky 1989, Summers 1983) 
have noted that these two broad asset classes appear to comove too little when one considers that any news about future riskfree rates should tend to push them in the same direction: the 1970's for example, were characterized by low stock market valuations in spite of low real interest rates, while the 1980's brought a sustained rise in the stock market in spite of much higher real rates. Another striking example of divergence between bonds and stocks occurred in Fall 1998 following Russia's devaluation of the rouble and default on outstanding debt: bond prices rose sharply while the stock market fell.

Our model sheds light on such puzzling delinkages between the stock and bond markets through flows of funds from one asset class to another which push them in opposite directions. When applied to Fall 1998, our model effectively captures a "flight to quality" phenomenon, often discussed in the financial press.

\subsection{Volatility}

In our framework, prices of styles are excessively volatile, in the sense that they are more volatile than they would be in the absence of switchers, or equivalently, more volatile than news about dividends. In our numerical example,

$$
\frac{\operatorname{std}\left(\Delta P_{X, t}\right)}{\operatorname{std}\left(\Delta P_{X, t}^{*}\right)}=1.3>1
$$

The excess volatility in our model comes from two sources. First, and most obviously, it comes from switchers' use of adaptive expectations. An increase in style $X$ 's price due to good fundamental news attracts switcher flows which then push prices up more than fundamentals justify. The second mechanism operates through the externality. Good news about a competing style $Y$ generates switcher flows into $Y$ and out of $X$, thus moving $X$ 's price even if there is no fundamental news about $X$.

Shiller (1981) and Le Roy and Porter (1981) find evidence of excess volatility in the aggregate U.S. stock market, while Campbell (2000) documents excess volatility in a large number of international stock markets. Our model is consistent with this evidence. Above and beyond that, it predicts that specific equity styles will also exhibit excess volatility: the prices of small stocks, growth stocks, and of individual industry portfolios should also move more than is justified by their fundamentals.

Our model also predicts that excess volatility will be higher at the style level than at the individual stock level. In our numerical example,

$$
\frac{\operatorname{std}\left(\Delta P_{X, t}\right)}{\operatorname{std}\left(\Delta D_{X, t}\right)}=1.3>1.1=\frac{\operatorname{std}\left(\Delta P_{i, t}\right)}{\operatorname{std}\left(\Delta D_{i, t}\right)} .
$$


This is a direct consequence of our results on comovement: since individual stocks comove more than is justified by fundamentals, the ratio of return volatility to fundamental volatility will be higher for styles than for individual stocks.

\subsection{Own- and Cross- Autocorrelations}

The presence of switchers in the market makes returns on a style positively autocorrelated in the short run, and negatively autocorrelated in the long run: a good return for style $X$ draws in switchers who push its price up again next period, inducing positive autocorrelation. The price swing is eventually reversed in the long run, creating mean-reversion.

The relative performance aspect of our framework, and in particular the externality that it creates, lead to additional predictions about cross-autocorrelations across styles, namely that they should be negative in the short run and positive in the long run. A good return on style $X$ at time $t$ generates outflows from $Y$ into $X$, pushing $Y$ 's price down at time $t+1$. In the long run, $Y$ 's price recovers, generating positive cross-autocorrelations at longer lags.

Table 1 shows the magnitude of these own- and cross-autocorrelations for our particular numerical example. The first order own-autocorrelation is 0.53 , while the correlation of returns nine lags apart is -0.2 . These positive autocorrelations appear large but should be interpreted carefully. Recall that these figures are computed for the case of just two styles: at every moment in time, both styles are subject to the effects of switchers, who are either adding money to a style, or pulling it out, resulting in strong serial correlation. In reality, investors choose from many different styles, and at any one moment, only a few of them are subject to the effect of switchers; the others are relatively untouched. Competition among multiple styles will attenuate the autocorrelations.

In making predictions, we again need to keep in mind that in reality, there is likely to be overlap in styles not captured in our simple model: stocks will be affected both by flows into the stock market as a whole, as well as by intra stock market flows between styles. We would therefore expect aggregate U.S. and international stock markets to be positively (negatively) autocorrelated at short (long) horizons, and also industry portfolio returns net of market returns, value and growth portfolio returns net of market returns, and small and large stock portfolio returns net of market returns to be positively (negatively) autocorrelated at short (long) horizons.

The available evidence on autocorrelations is consistent with our analysis. Poterba and Summers (1988) find that monthly aggregate U.S. stock returns as well as international stock indices are positively autocorrelated at horizons up to a year, and negatively autocorrelated thereafter. Cutler, Poterba, and Summers (1991) find the same effect in the bond market, as well as in real estate and commodity markets. 
Our simulated data also shows us the autocorrelation structure of individual stocks. For our particular numerical example, it has the form ${ }^{10}$

$$
\operatorname{corr}\left(\Delta P_{t}, \Delta P_{t+1}\right)=\left(\begin{array}{cc}
\widehat{A} & \widehat{B} \\
\widehat{B} & \widehat{A}
\end{array}\right)
$$

with

$$
\widehat{A}=\left(\begin{array}{llll}
0.22 & 0.22 & \cdots & 0.22 \\
0.22 & \ddots & \ddots & \vdots \\
\vdots & \ddots & \ddots & 0.22 \\
0.22 & \cdots & 0.22 & 0.22
\end{array}\right), \widehat{B}=\left(\begin{array}{llll}
-0.22 & \cdots & \cdots & -0.22 \\
\vdots & \ddots & & \vdots \\
\vdots & & \ddots & \vdots \\
-0.22 & \cdots & \cdots & -0.22
\end{array}\right) \text {. }
$$

Note that the positive own-autocorrelation at the style level induces a very substantial positive cross-autocorrelation of 0.22 between stocks in the same style: a good return on style $X$ this period is likely to be followed by a good return in the next, making stocks within a style positively cross-autocorrelated. Meanwhile, the negative cross-autocorrelation between styles induces negative cross-autocorrelations between stocks in different styles.

\subsection{Style-level Momentum and Contrarian Strategies}

When switchers affect prices, style-level momentum or "style-chasing" strategies are profitable. A style-level momentum strategy buys into styles with good recent performance and avoids styles that have done poorly. Such strategies are successful because they take advantage of the price movements caused by switchers as they move funds across styles: good performance by a style attracts switcher flows which then drive the price even higher. A strategy that anticipates this and jumps ahead of the switcher flows is likely to do well.

A simple way of implementing a style-chasing strategy is through the following share demands:

$$
\begin{aligned}
N_{i, t} & =\frac{1}{n}\left[\Delta P_{X, t}-\Delta P_{Y, t}\right], i \epsilon X, \\
N_{j, t} & =\frac{1}{n}\left[\Delta P_{Y, t}-\Delta P_{X, t}\right], j \epsilon Y .
\end{aligned}
$$

A straightforward calculation shows that the average profit from such a strategy can be decomposed into three components: ${ }^{11}$

$$
\begin{aligned}
& E\left[\sum_{l} N_{l, t} \Delta P_{l, t+1}\right] \\
= & {\left[\operatorname{cov}\left(\Delta P_{X, t}, \Delta P_{X, t+1}\right)+\operatorname{cov}\left(\Delta P_{Y, t}, \Delta P_{Y, t+1}\right)\right] }
\end{aligned}
$$

\footnotetext{
${ }^{10}$ This is a $2 n \times 2 n$ matrix whose $(i, j)$ element is $\operatorname{corr}\left(\Delta P_{i, t}, \Delta P_{j, t+1}\right)$.

${ }^{11} \mathrm{By}$ average profit, we mean average one period change in wealth from implementing the strategy.
} 


$$
\begin{aligned}
& -\left[\operatorname{cov}\left(\Delta P_{X, t}, \Delta P_{Y, t+1}\right)+\operatorname{cov}\left(\Delta P_{Y, t}, \Delta P_{X, t+1}\right)\right] \\
& +\left[E\left(\Delta P_{X, t}-\Delta P_{Y, t}\right)\right]^{2} .
\end{aligned}
$$

The first component depends on style own-autocorrelations, the second on cross-autocorrelations, and the third on cross-sectional dispersion in average style returns. In the previous section, we showed that in the presence of switchers, short run own-autocorrelations are positive, and short run cross-autocorrelations are negative. All three components in the decomposition are therefore positive, making style momentum a profitable strategy.

To illustrate this, we compute Sharpe ratios for a number of different investment strategies: strategy (A) adheres to style $X$ throughout, (B) adheres to style $Y$ throughout, and (C) follows the momentum strategy in (27), where the investor goes long the style which outperformed in the previous period, and short the other style. Table 2 reports the Sharpe ratios, both when switchers are present and when they are not. The table confirms our prediction that when switchers play a role in setting prices, style-based momentum strategies offer attractive Sharpe ratios. ${ }^{12}$

A number of existing studies examine style-chasing strategies. In all cases, their evidence supports our analysis. Moskowitz and Grinblatt (2000) show that a momentum strategy based on industry portfolios is profitable; Lewellen (1999) investigates a momentum strategy using size-sorted portfolios, and finds it to be successful. Richards (1996) and Asness, Porter, and Stevens (1997) show that a momentum strategy works well when applied to country portfolios.

Also consistent with our model, Haugen and Baker (1996) track returns on a large number of investment styles and show that a strategy which tilts towards styles with good prior performance earns very high risk-adjusted returns - higher than the returns on any one style. They successfully replicate their findings in out-of-sample tests in a number of international markets.

Our model also predicts that in many situations, style-based contrarian strategies will be successful. In a simple contrarian strategy, the investor goes long if a style is trading at a price $P$ below its fundamental value $P^{*}$, and short otherwise:

$$
\begin{aligned}
N_{i, t} & =\frac{1}{n}\left[P_{X, t}^{*}-P_{X, t}\right], i \epsilon X, \\
N_{j, t} & =\frac{1}{n}\left[P_{Y, t}^{*}-P_{Y, t}\right], j \epsilon Y .
\end{aligned}
$$

These strategies should work because they buy into styles whose prices have been pushed below fundamental value by switcher outflows, and can be expected to correct in the future.

\footnotetext{
${ }^{12}$ The Sharpe Ratio we compute is the mean one period change in wealth from implementing the strategy divided by the standard deviation of the one period change in wealth.
} 
Table 2 also reports the Sharpe Ratio of the contrarian strategy in (29), which we label Strategy D. The Sharpe ratio is indeed positive, although not nearly as impressive as that for the momentum strategy.

Evidence on the performance of style-based contrarian strategies is more limited. Asness, Porter, and Stevens (1997) show that a contrarian strategy applied to country portfolios works well, and our model predicts that an industry-based strategy will also be successful.

In our model, momentum and contrarian strategies implemented at the individual stock level are also profitable. ${ }^{13}$ However, our framework makes the strong prediction that the success of these individual stock level strategies is driven by style level phenomena. In this regard, Moskowitz and Grinblatt's work on industry momentum is particularly significant because they show that the well-known evidence on momentum in individual stocks (see Jegadeesh and Titman, 1993) is largely generated at the industry level, exactly the prediction of our model.

\section{Special Styles}

An important style that deserves further discussion is indexation. The ideas in the previous section apply as much to an index style as they do to a style like "new economy" stocks. An index may experience long and substantial deviations from fundamental value: investors may see an index do well, buy into it, push its price up still further and thus attract further buyers. This can lead to years of superior performance for the index relative to the overall market, whatever its fundamental news. Moreover, stocks within an index should comove more than their fundamentals and a stock which is added to an index should comove more with the index after inclusion than before. Indices should display excess volatility and be positively (negatively) autocorrelated at short (long) horizons.

One issue which makes indexation different from other styles is that it is not obvious what investors compare indexation to when they are deciding whether to index. One possibility is that switchers compare indexers to active managers, who hold a mix of stocks in the index and outside it. This in turn raises the possibility that active managers may strategically alter the proportion of stocks within the index that they hold so as to control the key variable that switchers pay attention to, namely performance relative to the index. For example, if an index enters a switcher-driven period of high returns, active managers may increase their holdings of stocks in the index, reducing their tracking error relative to the index in order to slow down outflows from their funds.

\footnotetext{
${ }^{13}$ Other explanations for the success of such strategies can be found in Barberis, Shleifer, Vishny (1998), Daniel, Hirshleifer, Subrahmanyam (1998), and Hong and Stein (1999).
} 
Another interesting issue arises with price-dependent styles, where the characteristic defining the style depends on price. Many common styles such as "small stocks" or "value stocks" fall into this category. When a style is price-dependent, its composition may change. Suppose that switchers have kicked off a long upswing in the price of small stocks relative to their fundamentals: they buy small stocks, pushing up their price, which attracts more switchers, and so on. After a while, some of the small stocks experience price increases so large that they cannot be considered small any more, and are no longer part of the small stock style.

This change in composition need not brake the evolution of the small stock style itself. However, it may mean that the degree of misvaluation experienced by any individual asset is lower than in the case where the style characteristic is not price-dependent: if a small stock becomes too highly valued relative to its fundamentals, it ceases to be a small stock and the buying pressure from switchers following the small stock style eases off, halting its ascent. This argument depends on the correlation between characteristic and price being negative: the higher a stock's price, the less likely it is to be a small stock. When this correlation is positive, misvaluation of individual stocks is more severe when the style is price-dependent than when it is not.

\section{$6 \quad$ Estimating Style Premia}

Academics and practitioners are frequently interested in estimating the mean return of a portfolio of stocks with some particular characteristic, or of a style, in our terminology. This is not an easy task: even after seeing many years of data, an estimate of the mean based on the sample average of style returns is typically very imprecise (Merton, 1980).

In an economy with switchers, using the sample mean to estimate the true mean is even more hazardous. As we saw in Section 3, fund flows from switchers may generate several years of strikingly good returns on a style, raising the style's sample mean. These high returns are not evidence of a high true mean: they are simply due to transitory inflows from switchers, and as such, are eventually reversed. In the presence of switchers, then, the sample mean can deviate from the true mean more than usual, making it an even more imprecise estimator.

To illustrate the problem, recall that when researchers want to estimate the true mean $\mu$ of a style, they take return data for the style over $\tau$ periods, $r_{1}, \ldots, r_{\tau}$, say, compute the sample mean $\bar{r}$, and then assign this estimate a standard error of $\frac{\sigma_{r}}{\sqrt{\tau}}$, where $\sigma_{r}$ is the sample standard deviation of style returns.

To see if this is a useful measure of the accuracy of the sample mean in the presence of 
switchers, we use the price formula (22) together with the parameters in (24) and (25) to create simulated data for 100 stocks over $\tau$ periods. We compute the mean return of style $X$ in this sample - the mean return of the first 50 stocks, to be precise - and then repeat the process 1000 times with 1000 different data sets, recomputing the mean of style $X$ each time. Finally, we calculate the standard deviation of these 1000 sample means. Table 3 reports results for sample sizes $\tau=10,20,30,40$, and 50, alongside the usual measure of sample mean standard deviation $\frac{\sigma_{r}}{\sqrt{\tau}}$. In our simulated data, $\sigma_{r}=0.75$.

Table 3 shows that in the presence of switchers, sample means are generally more volatile than the $\frac{\sigma_{r}}{\sqrt{\tau}}$ measure would suggest. Put differently, the sample mean is less accurate a measure of the true mean when switchers are around. As a technical matter, the reason for this is that the $\frac{\sigma_{r}}{\sqrt{\tau}}$ measure assumes that returns are uncorrelated; however, switchers introduce bursts of positive serial correlation into returns, making sample means more volatile.

Fama and French (2000) make essentially the same point in the context of estimating the equity premium. They point out that changes in the discount rate used by investors lead to big changes in stock prices which affect the in-sample average return a lot but carry little information about the true long run mean return of stocks. In this way, changes in discount rates reduce the precision of the sample mean estimator. In our model, flows from switchers that are unrelated to cashflows implicitly change the discount rate, with identical consequences. Motivated by this point, Fama and French go further and suggest that an alternative estimator based on the dividend-discount model offers a more precise estimate of the true underlying mean.

As a practical matter, the fact that switchers can reduce the accuracy of sample means as estimates of true means suggests a more cautious approach to interpreting historical premia. Suppose that a style experiences several successive years of high returns. A careful investor will worry that the high returns are simply due to sustained, but temporary, inflows from switchers, and therefore not representative of a genuinely high underlying mean $\mu$. Conversely, if a style experiences a few years of poor returns, it is important to bear in mind that the lackluster returns may be due to temporary outflows driven by switchers and are not necessarily an indication of a low true mean $\mu$.

To put this in historical context, consider again the case of small stocks. The stellar performance of this style from 1975-1983 strengthened many observers' belief in the existence of a small stock premium. A different view is that those good years were simply due to inflows from switchers and therefore not representative of a true premium. Such a theory would also predict that after those impressive years, small stocks should experience poor returns as the mispricing is corrected, so that recalculating the sample mean several years later should give substantially lower numbers. This prediction is consistent with actual experience.

Along similar lines, the 1995-2000 stretch of high returns on the aggregate stock market 
might be viewed as yet more evidence that stocks have an underlying mean $\mu$ that is much higher than that of bonds. However, if these good years are due to switcher inflows, such an inference is not warranted. Finally, the poor performance of value stocks in 1998-1999 after several decades of high returns has led some to question whether value strategies really earn the genuine long term premium many observers believe they do. A switcher-based view suggests that the bad years may be due to switcher outflows, triggered by the success of the competing growth style, and hence not necessarily a reason for long term pessimism.

The fact that sample means may be especially imprecise estimators of true means in the presence of switchers raises the question of whether there are alternative estimators that would serve the investor better. One possibility would make use of the externality introduced by the relative performance feature of our model: the true mean of a style $X$ may be better estimated using information in the sample mean of a competing style $Y$, even if the investor has no reason to believe that the true means are related in any way. To see this, suppose that the sample mean of style $X$ is $\bar{X}=10 \%$, and of style $Y$ is $\bar{Y}=-5 \%$. Assume also - and this is key - that the investor believes that the true means on both styles are positive, perhaps because risk-aversion typically implies positive risk premia. Seeing that $\bar{Y}$ has a negative sample mean, the investor infers that style $Y$ must have experienced negative shocks relative to its true mean over this sample period. Since he believes in the importance of switchers, he knows that shocks to the two styles are contemporaneously negatively correlated, telling him that style $X$ has probably experienced positive shocks relative to its true mean over this sample period, and hence that its true mean is probably less than $10 \%$.

\section{Optimal Investment Strategies in the Presence of Switchers}

If an arbitrageur believes that switchers play an important role in setting prices, what kind of strategies will he choose to use? In Section 4.5, we considered two possibilities: a style momentum or "style-chasing" strategy, which invests in styles which have had good recent performance; and also a style contrarian strategy, which invests in styles with poor performance over an extended prior period of time.

Table 4 reports Sharpe ratios for these strategies in an economy with switchers. Strategy (C) is style momentum, while strategy (D) is the contrarian strategy. Strategies (A) and

(B) invest in styles $X$ throughout and in style $Y$ throughout, respectively. For parameters other than $\theta$, we use the values in (24) and (25), and for $\theta$, we consider a range of values. In Section 4.5 , we used a $\theta$ of 0.95 , so the results for that case are identical to those in Table 2; the results for $\theta=0.65$ and $\theta=0.35$ are new to this section. 
As noted in Section 4.5, the momentum and contrarian strategies are profitable relative to strategies that adhere to only one style. However, the momentum strategy is by far the most attractive of strategies (A)-(D) across all values of $\theta$ that we try. This is particularly true for high $\theta$, where switcher flows into styles are very persistent, and mispricings take a long time to correct. In these cases, it makes much more sense for the arbitrageur to ride with the switchers, rather than to try to bet against them. For lower values of $\theta$, switcher flows are less persistent and prices revert to fundamental value more quickly. This makes the contrarian strategy more attractive, although it still remains a distant second to the momentum strategy.

Our results are consistent with the finding of De Long et. al. (1990a) who use a simple model to show that when arbitrageurs are included along with trend-chasing investors, they choose to follow a style-chasing, or momentum strategy. This is important because it suggests that arbitrageurs will not be effective in correcting mispricing caused by switchers. If an asset is overpriced, arbitrageurs prefer to buy the asset in expectation of further appreciation than to sell or short it. As a result, they exacerbate rather than attenuate the effect of switchers.

We can go one step further and compute the optimal strategy for an arbitrageur who is clever enough to figure out the exact demand function (5) used by switchers. To enable a direct comparison with the style momentum and contrarian strategies, we restrict the arbitrageur to style level strategies in which demand for all assets within the same style is identical:

$$
\begin{aligned}
N_{i, t} & =\frac{1}{n} N_{X, t}, i \epsilon X, \\
N_{j, t} & =\frac{1}{n} N_{Y, t}, j \epsilon Y .
\end{aligned}
$$

Given capital of $W^{A}$ at time $t$, he solves ${ }^{14}$

$$
\begin{aligned}
& \max _{N_{i, t}, N_{j, t}} E_{t}^{A}\left(-\exp \left[-\gamma\left(W^{A}+\sum_{i \in X} N_{i, t} \Delta P_{i, t+1}+\sum_{j \in Y} N_{j, t} \Delta P_{j, t+1}\right)\right]\right) \\
= & \max _{N_{X, t}, N_{Y, t}} E_{t}^{A}\left(-\exp \left[-\gamma\left(W^{A}+N_{X, t} \Delta P_{X, t+1}+N_{Y, t} \Delta P_{Y, t+1}\right)\right]\right),
\end{aligned}
$$

to obtain

$$
\left(\begin{array}{c}
N_{X, t}^{A} \\
N_{Y, t}^{A}
\end{array}\right)=V^{-1}\left(\begin{array}{c}
\frac{1}{\gamma} E_{t}^{A}\left(P_{X, t+1}-P_{X, t}\right) \\
\frac{1}{\gamma} E_{t}^{A}\left(P_{Y, t+1}-P_{Y, t}\right)
\end{array}\right)
$$

where $V$ is the covariance matrix of returns.

Since he knows that prices are determined by (22), he is able to conclude that

$$
E_{t}^{A}\left(P_{X, t+1}-P_{X, t}\right)=\frac{1}{\phi} \Delta N_{X, t+1}^{S} \equiv \frac{1}{\phi}\left(N_{X, t+1}^{S}-N_{X, t}^{S}\right),
$$

\footnotetext{
${ }^{14}$ The "A" superscript in these expressions stands for arbitrageur.
} 


$$
E_{t}^{A}\left(P_{Y, t+1}-P_{Y, t}\right)=-\frac{1}{\phi} \Delta N_{X, t+1}^{S}
$$

where from (11),

$$
\Delta N_{X, t+1}^{S}=\frac{\Delta P_{X, t}-\Delta P_{Y, t}}{2}-(1-\theta) \sum_{k=1}^{t} \theta^{k-1}\left(\frac{\Delta P_{X, t-k}-\Delta P_{Y, t-k}}{2}\right) .
$$

In the simple case where both styles have equal return variance, equation (30) reduces to

$$
\begin{aligned}
N_{X, t}^{A} & =c \Delta N_{X, t+1}^{S}, \\
N_{Y, t}^{A} & =-c \Delta N_{X, t+1}^{S},
\end{aligned}
$$

where $c$ is a constant that depends on the covariance matrix of returns.

In other words, the optimal strategy involves going long a certain number of shares in one style, and short an equal number in the other. Looking at (32) and (33) more closely shows that the optimal strategy essentially combines a momentum and a contrarian strategy. The first term in (32) is a momentum component, because it pushes the arbitrageur to allocate more to style $X$ if style $X$ did well in previous period. The second set of terms in (32) form a contrarian component, pushing the arbitrageur to allocate less to style $X$ if $X$ has done well over an extended recent period of time.

Table 4 reports the Sharpe ratio for this optimal strategy, labelled strategy (E). For high $\theta$, the momentum strategy and the optimal strategy have almost identical Sharpe ratios. This makes sense given (32): when $\theta$ is close to 1 , the second set of terms is downweighted, making the optimal strategy essentially a momentum strategy. As $\theta$ falls, the second set of terms in (32) becomes more important, giving the optimal strategy more of a contrarian flavor. This is consistent with the improved performance of contrarian strategies for low $\theta$.

In reality, even an investor who believes in the existence of switchers is unlikely to be able to figure out their exact demand function. This observation raises the central problem for rational arbitrage. On the one hand, a rational arbitrageur might wish to style-chase, recognizing that such "reflexive" trading, in the language of Soros (1987), might bring high returns. On the other hand, reflexive trading calls for taking long positions in overpriced securities and short positions in underpriced securities, and hence runs the substantial risk that prices return to fundamentals faster than one expects. Similarly, while the contrarian strategy can also earn high abnormal returns in the long run, it has short run risks as well. Specifically, the arbitrageur must be able and willing to sustain the short run losses as the trend continues, which he might not be able to do if his resources or horizon is limited (De Long et. al., 1990b, Shleifer and Vishny 1997). Whatever the strategy the rational arbitrageur chooses, it is fraught with risks, which suggests that the phenomena we describe in this paper may influence financial markets over long periods of time. 


\section{Conclusion}

The model of financial markets discussed in this paper is in many ways similar to that proposed by Black (1986). On the one hand, financial markets are not efficient. Prices deviate substantially from fundamental values as styles become extremely popular or unpopular. Such price deviations can easily look like bubbles. If an observer knows what is going on, there are substantial, though risky, profits to be made from a combination of contrarian and momentum trading. On the other hand, despite the fact that markets are inefficient, prices are extremely noisy. Patterns in security prices are complex, and may change significantly over time. Without knowing which style or model is favored, arbitrage is very risky and there are no consistent profits to be had. Moreover, the analysis is fraught with the danger of finding patterns where none exist. To some people such markets might even appear to be efficient.

Such markets are not entirely anarchic, however. They do exhibit long run pressures toward fundamentals. Moreover, there are empirical predictions that one can make about security prices in such markets, including excess comovement. In this paper, we have only begun to scratch the surface of such markets. It is possible that further predictions will emerge as we look at financial markets from the perspective of style investing. 


\section{References}

Asness, C., Liew J., and R. Stevens (1997), "Parallels Between the Cross-sectional Predictability of Stock Returns and Country Returns," Journal of Portfolio Management 23, 79-87.

Baca, S., Garbe B., and R. Weiss (2000), "The Rise of Sector Effects in Major Equity Markets," Financial Analysts Journal 56, 34-40.

Banz, R. (1979), "The Relationship between Return and Market Value of Common Stocks," Journal of Financial Economics 9, 3-18.

Barberis, N., Shleifer A., and R. Vishny (1998), "A Model of Investor Sentiment," Journal of Financial Economics 49, 307-343.

Barksy, R. (1989), "Why Don't the Prices of Stocks and Bonds Move Together?," American Economic Review 79, 1132-1145.

Bernstein, R. (1995), Style Investing, New York: Wiley.

Black, F. (1986), "Noise," Journal of Finance 41, 529-43.

Campbell, J.Y. (2000), "Asset Prices, Consumption, and the Business Cycle," in J. Taylor and M. Woodford eds. Handbook of Macroeconomics, Volume 1, North Holland.

Cavaglia S., Brightman C., and M. Aked (2000), "The Increasing Importance of Industry Factors," Financial Analysts Journal 56, 41-54.

Chan L., Karceski J., and J. Lakonishok (2001), "A New Paradigm or the Same Old Hype? The Future of Value Versus Growth Investing," forthcoming, Financial Analysts Journal.

Cutler, D., Poterba J., and L. Summers (1991), "Speculative Dynamics," Review of Economic Studies 58, 529-46.

Daniel, K., Hirshleifer D., and A. Subrahmanyam (1998), "Investor Psychology and Security Market Under- and Overreactions," Journal of Finance 53, 1839-85.

De Long, B., Shleifer A., Summers L., M. Waldmann (1990a), "Positive Feeback Investment Strategies and Destabilizing Rational Speculation," Journal of Finance 45, 375-95.

De Long, B., Shleifer A., Summers L., and M. Waldmann (1990b), "Noise Trader Risk in Financial Markets," Journal of Political Economy 98, 703-38. 
Fama, E., and K. French (1992), "The Cross-section of Expected Stock Returns," Journal of Finance 47, 427-465.

Fama, E., and K. French (1995), "Size and Book-to-Market Factors in Earnings and Returns", Journal of Finance 50, 131-155.

Fama, E., and K. French (2000), "The Equity Premium," Working Paper, University of Chicago.

Froot, K., and E. Dabora (1999), "How are Stock Prices affected by the Location of Trade?," Journal of Financial Economics 53, 189-216.

Goetzmann, W., Massa M., and K. Rouwenhorst (2000), "Behavioral Factors in Mutual Fund Flows," Working Paper, Yale School of Management.

Gompers P., and A. Metrick (2001), "Institutional Investors and Equity Prices," forthcoming, Quarterly Journal of Economics.

Graham, B., and D. Dodd (1934), Security Analysis, New York: McGraw Hill.

Harris, L., and E. Gurel (1986), "Price and Volume Effects Associated with Changes in the S\&P 500: New Evidence for the Existence of Price Pressure," Journal of Finance 41, 851-860.

Haugen, R., and N. Baker (1996), "Commonality in the Determinants of Expected Stock Returns," Journal of Financial Economics 41, 401-439.

Hong H., and J. Stein (1999), "A Unified Theory of Underreaction, Momentum Trading and Overreaction in Asset Markets," Journal of Finance 54, 2143-2184.

Jegadeesh, N., and S. Titman (1993), "Returns to Buying Winners and Selling Losers: Implications for Stock Market Efficiency," Journal of Finance 48, 65-91.

Kaminsky, G., Lyons R., and S. Schmukler (2000), "Managers, Investors, and Crises: Mutual Fund Strategies in Emerging Markets," NBER Working Paper 7855.

Kaul, A., Mehrotra V., and R. Morck (2000), "Demand Curves for Stocks Do Slope Down: New Evidence from an Index Weights Adjustment," Journal of Finance 55, 893-912.

Kindleberger, C. (1978), Manias, Panics, and Crashes, New York: Basic Books.

Lamont, O., and R. Thaler (2000), "Can the Market Add and Subtract? Mispricing in Tech Stock Carveouts," Working Paper, University of Chicago. 
Lee, C., Shleifer A., and R. Thaler (1991), "Investor Sentiment and the Closed-end Fund puzzle," Journal of Finance 46, 75-110.

LeRoy, S., and R. Porter (1981), "The Present Value Relation: Tests Based on Variance Bounds," Econometrica 49, 555-577.

Lewellen J. (1999), "Momentum Profits and the Autocorrelation of Returns," Working Paper, Sloan School of Management.

Merton R. (1980), "On Estimating the Expected Return on the Market: An Exploratory Investigation," Journal of Financial Economics 8, 323-361.

Moskowitz, T., and M. Grinblatt (1999), "Do Industries Explain Momentum?," Journal of Finance 54, 1249-1290.

Mullainathan, S. (2000), "Thinking Through Categories," Working Paper, MIT.

Pindyck R., and J. Rotemberg (1990), "The Excess Comovement of Commodity Prices," Economic Journal 100, 1173-1189.

Poterba, J. and L. Summers (1988), "Mean Reversion in Stock Returns: Evidence and Implications," Journal of Financial Economics 22, 27-59.

Richards, A. (1996), "Winner-Loser Reversals in National Stock Market Indices: Can They Be Explained?," Journal of Finance 52, 2129-2144.

Rosch, E., and B. Lloyd (1978), Cognition and Categorization, New Jersey: Lawrence Erlbaum Associates.

Rouwenhorst, G. (1999), "European Equity Markets and the EMU," Financial Analysts Journal 55, 57-64.

Shiller, R., (1981), "Do Stock Prices Move Too Much to be Justified by Subsequent Changes in Dividends?," American Economic Review 71, 421-36.

Shleifer A. (1986), "Do Demand Curves for Stocks Slope Down?," Journal of Finance 41, 579-590.

Shleifer A. (2000), Inefficient Markets: An Introduction to Behavioral Finance, Oxford University Press.

Shleifer A., and R. Vishny (1997), "The Limits of Arbitrage," Journal of Finance 52, 35-55. 
Siegel, J. (1999), Stocks for the Long Run, New York: McGraw Hill.

Soros G. (1987), The Alchemy of Finance, New York: John Wiley \& Sons.

Summers, L. (1983), "The Nonadjustment of Nominal Interest Rates: A Study of the Fisher Effect," in J. Tobin, ed., Macroeconomic Prices and Quantities: Essays in Memory of Arthur Okun, Brookings Institution.

Swensen, D. (2000), Pioneering Portfolio Management, The Free Press.

Vuolteenaho, T. (1999), "What Drives Firm-level Stock Returns?," Working Paper, Harvard University.

Wilson, R., and F. Keil (1999), The MIT Encyclopedia of the Cognitive Sciences, Cambridge, Mass: MIT Press. 


\section{Appendix}

\section{Deriving relative performance}

In this section, we show that adaptive expectations combined with a desire to maintain overall equity holdings at some target level, lead to demand functions that are based on relative performance. Suppose that at the start of each period, switchers are instructed to oversee the investment of an amount $W^{S}$. These investors want to keep their overall risky asset allocation close to a preset target level of $\bar{W}^{S}$ with the remainder, $W^{S}-\bar{W}^{S}$, allocated to cash. They see their main task as deciding how the fixed amount $\bar{W}^{S}$ should be divided between the two risky styles that are available. Once the overall allocation to a style has been determined, the funds are split equally between the assets in that style. We suppose that switchers have CARA preferences defined over the value of their invested funds one period later. In other words, they solve

$$
\begin{aligned}
& \max _{\alpha_{X}} E_{t}^{S}\left(-\exp \left[-\gamma \bar{W}^{S}\left(\sum_{l \epsilon X} \frac{\alpha_{X}}{n} R_{l, t+1}+\sum_{l \epsilon Y} \frac{1-\alpha_{X}}{n} R_{l, t+1}\right)\right]\right) \\
= & \max _{\alpha_{X}} E_{t}^{S}\left(-\exp \left[-\gamma \bar{W}^{S}\left(\alpha_{X} R_{X, t+1}+\left(1-\alpha_{X}\right) R_{Y, t+1}\right)\right]\right),
\end{aligned}
$$

where

$$
\begin{aligned}
R_{X, t+1} & =\frac{1}{n} \sum_{l \in X} R_{l, t+1} \\
R_{Y, t+1} & =\frac{1}{n} \sum_{l \epsilon Y} R_{l, t+1} .
\end{aligned}
$$

Here $\alpha_{X}$ is the fraction of $\bar{W}^{S}$ allocated to style $X, \gamma$ controls switcher risk aversion, $E_{t}^{S}$ denotes their expectations at time $t$, and $R_{l, t+1}$ is the gross return on asset $l$ between time $t$ and $t+1$, defined as $\frac{P_{l, t+1}}{P_{l, t}}$. If switchers take style returns $R_{X, t}$ and $R_{Y, t}$ to be normally distributed, this leads to an allocation of

$$
\begin{aligned}
\alpha_{X} \bar{W}^{S} & =\left(\frac{\Delta_{X}}{\Delta}\right) \bar{W}^{S}+\frac{1}{\gamma \Delta} E_{t}^{S}\left(R_{X, t+1}-R_{Y, t+1}\right) \\
\alpha_{Y} \bar{W}^{S} & =\left(1-\frac{\Delta_{X}}{\Delta}\right) \bar{W}^{S}+\frac{1}{\gamma \Delta} E_{t}^{S}\left(R_{Y, t+1}-R_{X, t+1}\right)
\end{aligned}
$$

where $\alpha_{Y}$ is the fraction allocated to style $Y$ and where

$$
\begin{aligned}
\Delta_{X} & =\operatorname{Var}_{t}^{S}\left(R_{Y, t+1}\right)-\operatorname{Cov}_{t}^{S}\left(R_{X, t+1}, R_{Y, t+1}\right), \\
\Delta & =\operatorname{Var}_{t}^{S}\left(R_{X, t+1}\right)+\operatorname{Var}_{t}^{S}\left(R_{Y, t+1}\right)-2 \operatorname{Cov}_{t}^{S}\left(R_{X, t+1}, R_{Y, t+1}\right) .
\end{aligned}
$$

Consistent with the intuition given in the main text, these demand functions depend on relative expected returns, $E_{t}^{S}\left(R_{X, t+1}-R_{Y, t+1}\right)$ : the expected return on style $X$ affects the allocation to style $X$ but also has an equal and opposite effect on the allocation to style $Y$. 
Suppose now that switchers form adaptive expectations of future returns, so that

$$
E_{t}^{S}\left(R_{X, t+1}\right)=\theta E_{t-1}^{S}\left(R_{X, t}\right)+(1-\theta) R_{X, t-1},
$$

which implies

$$
E_{t}^{S}\left(R_{X, t+1}\right)=(1-\theta) \sum_{k=1}^{t-1} \theta^{k-1} R_{X, t-k} .
$$

Substituting into (35) gives

$$
\begin{aligned}
\alpha_{X} \bar{W}^{S} & =\left(\frac{\Delta_{X}}{\Delta}\right) \bar{W}^{S}+\frac{1-\theta}{\gamma \Delta} \sum_{k=1}^{t-1} \theta^{k-1}\left(R_{X, t-k}-R_{Y, t-k}\right), \\
\alpha_{Y} \bar{W}^{S} & =\left(1-\frac{\Delta_{X}}{\Delta}\right) \bar{W}^{S}+\frac{1-\theta}{\gamma \Delta} \sum_{k=1}^{t-1} \theta^{k-1}\left(R_{Y, t-k}-R_{X, t-k}\right) .
\end{aligned}
$$

To obtain the allocation for an individual asset in style $X$ or $Y$, simply divide these quantities by $n$. We think of the demand functions in (5) and (6) as approximations to the policies in (36) that preserve the feature most relevant for our analysis, namely the dependence on relative past performance. The approximations are useful because they lead to simpler expressions for prices. 
Table 1: Own autocorrelations of returns on style $X$ and cross autocorrelations between returns on styles $X$ and $Y$ in two economies, one with switchers and the other without.

\begin{tabular}{cll}
\hline & No switchers & With switchers \\
\hline $\operatorname{corr}\left(\Delta P_{X, t}, \Delta P_{X, t-k}\right)$ & & \\
$k=1$ & 0 & 0.53 \\
$k=2$ & 0 & 0.40 \\
$k=3$ & 0 & 0.25 \\
$k=4$ & 0 & 0.09 \\
$k=5$ & 0 & -0.01 \\
$k=6$ & 0 & -0.08 \\
$k=7$ & 0 & -0.13 \\
$k=8$ & 0 & -0.16 \\
$k=9$ & 0 & -0.20 \\
\hline $\operatorname{corr}\left(\Delta P_{X, t}, \Delta P_{Y, t-k}\right)$ & 0 & \\
$k=1$ & 0 & -0.51 \\
$k=2$ & 0 & -0.34 \\
$k=3$ & 0 & -0.22 \\
$k=4$ & 0 & -0.07 \\
$k=5$ & 0 & 0.02 \\
$k=6$ & 0 & 0.09 \\
$k=7$ & 0 & 0.16 \\
$k=8$ & 0 & 0.17 \\
$k=9$ & 0 & 0.19 \\
\hline
\end{tabular}


Table 2: Sharpe ratios of various strategies in two economies, one with switchers and the other without. Strategy (A) always invests in style X; strategy (B) always invests in style Y; strategy (C) is a style chasing strategy which invests each period in the style which did better in the previous period; strategy (D) is a style contrarian strategy which invests each period in styles trading below fundamental value at the start of the period. The parameter $\theta$ controls the persistence of switcher flows.

\begin{tabular}{lll}
\hline Strategy & $\theta=0.95$ & no switchers \\
\hline A & 0 & 0 \\
B & 0 & 0 \\
C & 0.59 & 0 \\
D & 0.11 & 0 \\
\hline
\end{tabular}

Table 3: Standard deviation of sample mean estimators in repeated samples for two economies, one with switchers and the other without. $\tau$ is the number of sample observations. $\frac{\sigma_{r}}{\sqrt{\tau}}$ is the standard deviation of the sample mean in the absence of switchers.

\begin{tabular}{lll}
\hline$\tau$ & $\frac{\sigma_{r}}{\sqrt{\tau}}$ & With switchers \\
\hline 10 & 0.23 & 0.38 \\
20 & 0.17 & 0.22 \\
30 & 0.14 & 0.15 \\
40 & 0.12 & 0.12 \\
50 & 0.11 & 0.11 \\
\hline
\end{tabular}


Table 4: Sharpe ratios of various strategies in an economy with switchers. Strategy (A) always invests in style X; strategy (B) always invests in style Y; strategy $(C)$ is a style chasing strategy which invests each period in the style which did better in the previous period; strategy (D) is a style contrarian strategy which invests each period in styles trading below fundamental value at the start of the period; strategy (E) is the optimal strategy for an arbitrageur who knows the form of switcher demand. The parameter $\theta$ controls the persistence of switcher flows.

\begin{tabular}{llll}
\hline Strategy & $\theta=0.95$ & $\theta=0.65$ & $\theta=0.35$ \\
\hline A & 0 & 0 & 0 \\
B & 0 & 0 & 0 \\
C & 0.59 & 0.50 & 0.44 \\
D & 0.11 & 0.21 & 0.31 \\
E & 0.61 & 0.58 & 0.57 \\
\hline
\end{tabular}




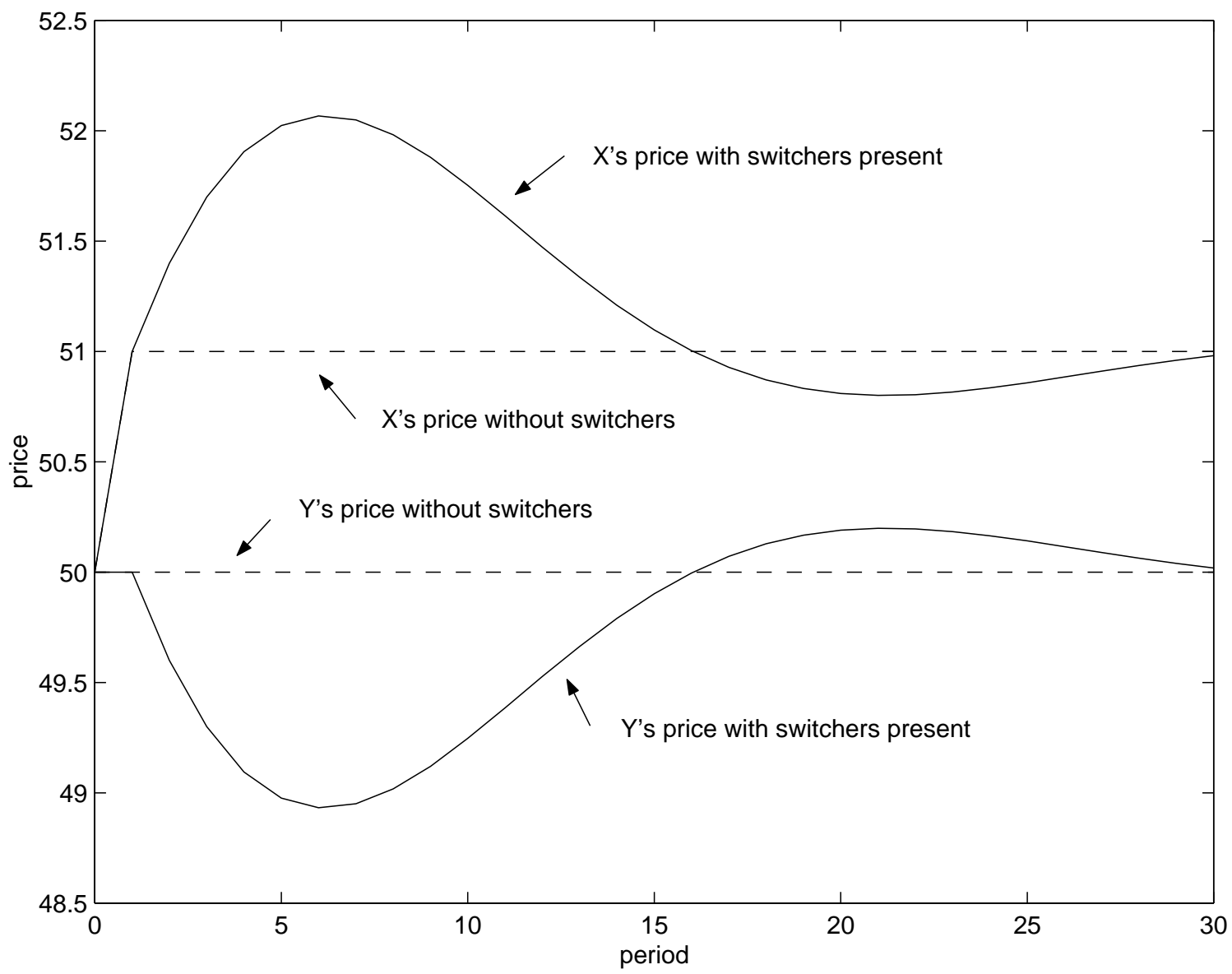

Figure 1. Impulse responses to a cashflow shock to style $\mathrm{X}$ in period 1. Prices of both $\mathrm{X}$ and $\mathrm{Y}$ are initially 50. Dashed lines indicate fundamental values, or prices without switchers. Solid lines indicate prices with switchers. 


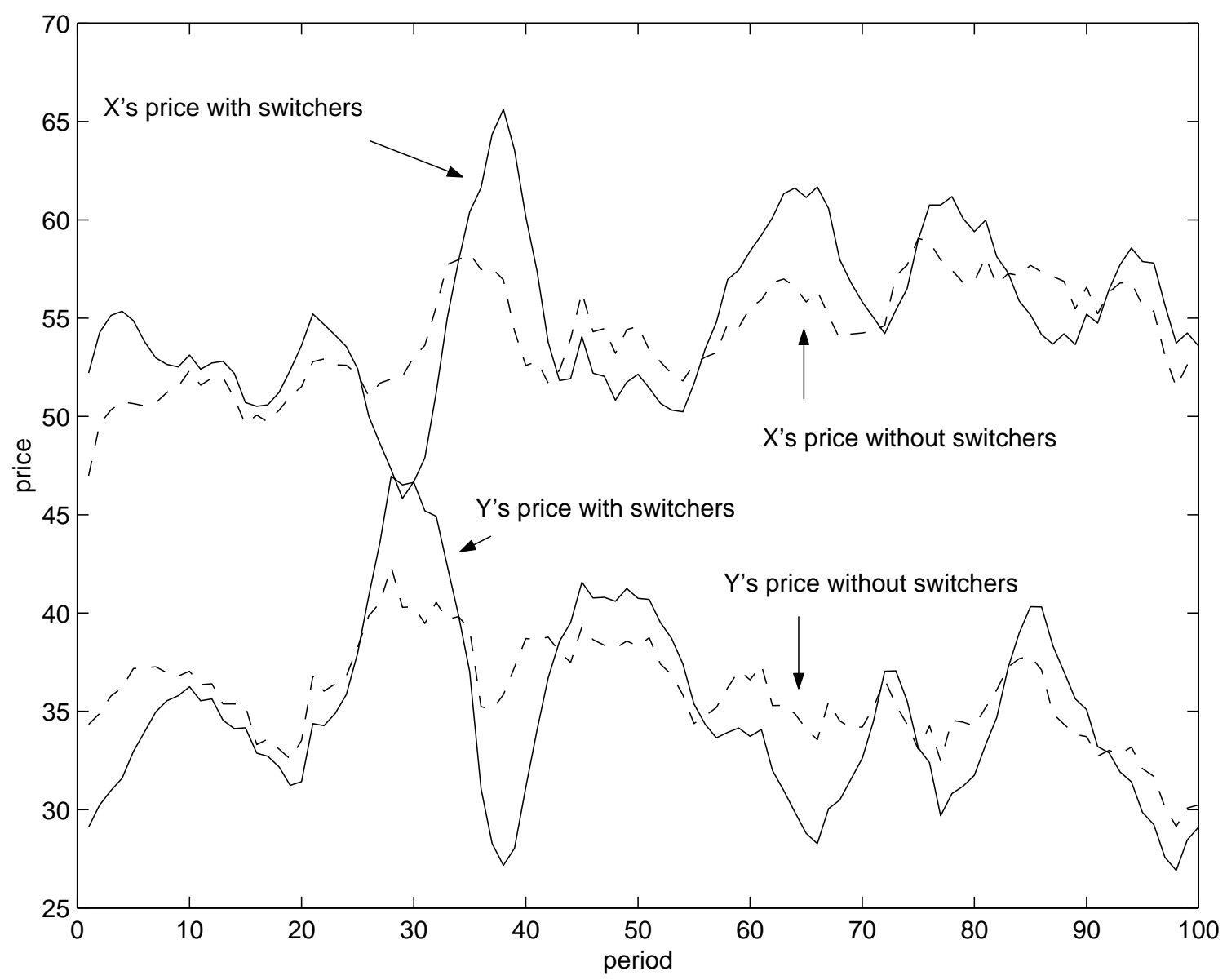

Figure 2. Price paths for two styles $\mathrm{X}$ and $\mathrm{Y}$. Dashed lines indicate fundamental values, or prices without switchers. Solid lines indicate prices with switchers. 